\title{
Is there a Reciprocity between Social and Financial Efficiency? A Case of Vietnam Microfinance Institutions
}

\author{
Quynh Anh Mai Nguyen \\ Graduate School of Global Studies, Doshisha University, \\ Karasuma-higashi-iru, Imadegawa-dori, Kamigyo-ku, Kyoto-shi 602-8580, Japan
}

\begin{abstract}
Efficiency evaluation does not mean how MFIs must gain, instead of how well MFIs manage their resources to achieve the dual missions of microfinance: social and financial objectives. This paper is an application of Data Envelopment Analysis (DEA) to contribute to different efficiency scores to specify missing aspects in microfinance study in Vietnam. MFIs in Vietnam are generally efficient with high overall technical efficiency, and NGO-sponsored Microfinance Programs are more socially efficient than other types. However, the efficiency scores have shown a significant difference between the social and financial performance. Overall social scores only reached $54.9 \%$, while the financial scores reached $92.8 \%$. The operational strategies of selected MFIs appear to be unsuccessful in serving poor women and reducing poverty. Instead, profitable activities, such as interest-based lending, are more concentrated. It is consistent with the view that in order to meet the social responsibilities, MFIs have to be at first financially sound. The evaluation of different efficiency forms also discovered the leading performers in the microfinance sector. These MFIs attained highefficiency scores on social and financial aspects, referring to the capability on cost control, operation improvement, and management activities.
\end{abstract}

Keywords: Microfinance, Social efficiency, Financial efficiency, Reciprocity, Vietnam

DOI: $10.7176 /$ RJFA/10-20-13

Publication date:October $31^{\text {st }}, 2019$

\section{Introduction}

Microfinance institutions (MFIs) are hybrid organizations with for-profit and social nature. Their operations have been forced to both improve the socio-economic wellbeing and set up income-generating activities of the deprived society/poor communities who are often ignored by the conventional banking system. Achieving the rapid growth across the world, the profitability potential of the microfinance industry has been attracting not only donors but also social investors. Many commercial banks and private sectors have recently engaged in MFIs with more efficient operations and better use of resources. As such, MFIs that are sustainable and efficient are more attracted than others. Because of the scare and limited resources, investors require for efficient use of funds for microfinance activities in the long run like other sectors (Rosenberg \& Nathan, 1994; Reynolds \& Thompson, 2002; Bruett et al., 2005; Kipesha, 2013). Efficient MFIs will perform well in allocating the input resources such as assets, personnel (number of loan officers), and funds to produce relevant outputs such as the number of clients, gross loan portfolio, and poverty outreach (Bassem, 2008, 2014).

Assessing the efficiency of MFIs is one of the critical measures toward benchmark organizations on overall performance, financial sustainability, and outreach level. Efficiency, better use of resources to maximize the production of the firms (Kipesha, 2013), refers to how well the MFIs utilize the inputs to deliver the optimal outputs. Efficiency evaluation does not mean how MFIs must gain, instead of how well MFIs manage their resources to achieve the dual missions of microfinance: social and financial objectives. MFIs pursue two conflicting goals that are coined as 'double bottom line' objectives, social ( $1^{\text {st }}$ bottom line), and financial $\left(2^{\text {nd }}\right.$ bottom line) goal (Gutierrez-Nieto, Serrano-Cinca, \& Mar Molinero, 2008; Galema et al., 2012; Azad et al., 2016). The $1^{\text {st }}$ goal emphasizes the social mission to moderate poverty. It measures the level in which microfinance services help marginalized communities getting out of the poverty trap. The $2^{\text {nd }}$ goal is the self-sustainability of MFIs without using subsidies, grants, and other concessional resources (Ahmad, 2011). It states that MFIs can make enough revenue to at least secure their operating and financial costs. Social and financial efficiency study in microfinance is then of much worth.

Efficiency evaluation of MFIs is indispensable for monitoring optimal policy implications in the 
microfinance industry, especially in developing countries like Vietnam. Although considerable reports and papers are attributing the performance of MFIs in Vietnam, the methodologies were mainly limited to traditional financial ratio analysis and descriptive analysis. However, these most common methodologies are hitherto not fit at capturing microfinance performance intensively. To the best of the author's survey, empirical evidence setting for evaluating the efficiency of Vietnam MFIs, especially the reciprocity between social and financial missions, is limited. Then, this paper contributes to different efficiency scores to specify missing aspects. Super efficiency scores were also calculated to rank the efficient MFIs and revealed the most efficient MFIs that are helpful for policymakers and would be good examples for other MFIs.

This paper aims to create models for estimating the practical aspects of the microfinance sector in Vietnam, focusing on social and financial efficiency. The result is supposed to reduce excessive inputs, which are inefficient and then to increase the capacity of MFIs. Moreover, it is to find out whether there is mutual support or the tradeoff between the two most important goals in the operation of MFIs, namely social and financial goals. The proposed findings may provide benchmarking tools to help decision-making about development strategy, and the evaluation of the relative position of each MFI enables a relative orientation regarding the operation.

After this introduction, section 2 discusses the methodology. Section 3 includes the variable selection and data. Section 4 explores the findings. Section 5 provides conclusions and suggestions.

\section{Methodology}

Efficiency study has attracted researchers in many fields, and its literature has developed all the time. However, there are little materials related to the microfinance industry compared with others, such as financing and banking sectors. Generally, measuring the efficiency level of MFIs can be done by using different (i) parametric methods and (ii) non-parametric methods (Berger \& Humphrey, 1997; Mokhtar et al., 2006; Gutiérrez-Nieto et al., 2008). Stochastic Frontier Approach (SFA) and Data Envelopment Analysis (DEA) are the two most popular tools with similar measurements. This present paper is an application of DEA to differentiate efficient MFIs from relatively inefficient MFIs. DEA technique is well suited in efficiency calculation as it accepts for multivariate analysis.

DEA, a parametric method, was proposed in 1978 by American operation research scientists (A.Charnes, W.W.Cooper, and E.Rhode, 1978), and has been commonly used to evaluate efficiency in almost every sector of the economy. It is non-parametric and a simple approach to extract the relative efficiency of production units. Using linear programming, DEA calculates the efficiency by comparison of aggregate input/output ratios of evaluation objects or Decision-Making Units or DMUs (MFIs in this study). DEA provides the best-practice efficient production frontier by combining efficient DMUs and "enveloping" those that are less efficient, which use higher costs for the same output or produce less output for the same input (Fuller and Crawford, 2011). DEA compares each DMU with only the "best" units.

DEA can be applied even though the conventional cost and profit function cannot be justified. It relates to the use of linear programming without any assumption of distribution and be free from an ex-ante specification of the functional forms of the relationship between inputs and outputs that are compulsory in statistical regression approaches. Moreover, DEA measures efficiency by using multiple inputs and multiple outputs in different measurement units without the need to standardize the data. Using DEA, one model can calculate the MFIs' dual goals of social and financial efficiency. More importantly, the small number of MFIs in Vietnam is also a motivation to select DEA as it is relatively less data-demanding as compared to other methods such as SFA. DEA assumes that all institutions have used similar resources and operate in a similar environment; the efficiency comparison would best perform within a single country (Bankenhol and Hudon, 2011). A limitation of DEA is that it ignores the measurement errors.

Standard assessment of efficiency in basic DEA commonly comprises two models: Charnes-Cooper-Rhodes (CCR) and Banker-Charnes-Cooper (BCC) model. The treatment of the nature of return-to-scale is their main difference (Akram et al., 2016). CCR is an optimization model that assumes that all DMUs operate with Constant Return-to-Scale (CRS), meaning no relationship between the scale of operation and the efficiency level. However, not all MFIs are operating at an optimal scale, and CCR results can be biased downward by scale inefficiency. Then, the BCC model, an extension of the CCR model, was proposed by Banker et al. in 1984 to allow the existence of Variable Return-to-Scale (VRS), the evaluation of efficiency that is not related to scaling efficiency.

There are three standard efficiency scores in DEA: overall/global Technical Efficiency (OTE/TE), local/pure Technical Efficiency (PTE), and Scale Efficiency (SE). These scores will help to explore the significant sources of inefficiencies among MFIs. 
The CCR model assumes the CRS production possibility set. For example, it postulated that the radial expansion and reduction of all observed DMUs and their non-negative combinations are possible. Hence, its score is called TE. The BCC model supposes that convex combinations of the observed DMUs from the production possibility set under VRS circumstances to achieve an optimal output, and its score is called PTE.

TE refers to DMUs' success in producing maximum output from a given set of input. There are $k$ DMUs using $n$ inputs to produce $m$ outputs. For each DMU $(\mathrm{k}=1, \ldots, \mathrm{k})$, inputs and outputs are denoted by $\mathrm{x}_{\mathrm{jk}}(\mathrm{j}=1, \ldots$, n) and $y_{i k}(i=1, \ldots, m)$ respectively. The following mathematical formulation calculates the efficiency of a DMU (Coelli et al., 2005; Worthington, 2000; Qayyum \& Ahmad, 2006).

$$
\mathrm{TE}=\frac{\text { sum of weighted output }}{\text { sum of weighted input }}=\mathrm{TE}_{\mathrm{k}}=\theta=\frac{\sum_{i=1}^{m} u_{i} y_{i k}}{\sum_{j=1}^{n} v_{j} x_{j k}}
$$

Where:

$\mathrm{y}_{\mathrm{ik}}$ : the quantity of the $\mathrm{i}^{\text {th }}$ output produced by the $\mathrm{k}^{\text {th }} \mathrm{DMU}$

$\mathrm{x}_{\mathrm{ik}}$ : the quantity of the $\mathrm{j}^{\text {th }}$ input used by the $\mathrm{k}^{\text {th }} \mathrm{DMU}$

$\mathrm{u}_{\mathrm{i}}, \mathrm{v}_{\mathrm{j}}$ : output and input weights

$\mathrm{TE}_{\mathrm{k}}$ : Technical Efficiency ratio

The efficiency score of a DMU cannot exceed 1 or $100 \%$, where the input and output weights are positive. The weights are calculated under the assumption that the DMU maximizes its efficiency.

$$
\left(\frac{\sum_{i=1}^{m} u_{i} y_{i k}}{\sum_{j=1}^{n} v_{j} x_{j k}}\right) \leq 1 \quad u_{i}, v_{j} \geq 0
$$

To determine the efficient frontier, the CCR and BCC model have two versions. First, an Output-Oriented linear programming Model (OOM) estimates the output of a DMU concerning the best-practice level of a given set of input. To select optimal weights, we follow the below mathematical programming (Wrothington, 2000; Coeli et al., 2005).

$\operatorname{Max} \mathrm{TE}_{\mathrm{k}}$

Subject to

$$
\begin{array}{lr}
\sum_{i=1}^{m} u_{i} y_{i r}-x_{j r}+w \leq 0 & \mathrm{r}=1 \ldots \mathrm{K} \\
v_{j} x_{j r}-\sum_{j=1}^{n} u_{j} x_{j k} & \mathrm{u}_{\mathrm{i}} \text { and } \mathrm{v}_{\mathrm{j}} \geq 0
\end{array}
$$

Second, the Input-Oriented linear programming Model (IOM) is applied to obtain the given level of output by minimizing the use of inputs. The mathematical programming model is as follows (Wrothington, 2000; Coeli et al., 2005):

$\operatorname{Min} \mathrm{TE}_{\mathrm{k}}$

Subject to

$$
\begin{array}{lr}
\sum_{i=1}^{m} u_{i} y_{i r}-y_{i F}+w \geq 0 & \mathrm{r}=1 \ldots \mathrm{K} \\
x_{j r}-\sum_{j=1}^{n} u_{j} x_{j k} \geq 0 & \mathrm{u}_{\mathrm{i}} \text { and } \mathrm{v}_{\mathrm{j}} \geq 0
\end{array}
$$

This model presents CRS if $w=0$, and it changed into VRS if $w$ is used unconstrained (Mostafa, 2009). The first case refers to TE, while the second case shows PTE.

If a DMU is fully efficient ( 1 or 100\%) in both the CCR and BCC scores, it is operating in the most efficient scale of production. Scale efficiency measures the capacity of a DMU being produced in CCR. However, if the efficient scores differ in the CCR and BCC model for a given DMU, it means that the institution presents a scale inefficiency. If a DMU, for example, has full BCC efficiency but a low CCR score, then it is local efficiency but not global efficiency due to the scale size of the DMU. Hence, it deserves to characterize the SE of a DMU by the ratio of two scores. Based on the results of the CCR and $\mathrm{BCC}$ model, SE is computed through the score difference (Cooper et al., 2006) as below:

$$
S E=\frac{T E_{C C R}}{T E_{B C C}} \quad \text { or } \quad T E_{C C R}=T E_{B C C} x S E=P T E x S E
$$

If the SE is less than one, the inefficiency may be caused by an inefficiency operation from the DMU (PTE), by disadvantageous environment under which the DMU is operating (SE), or both. The particular DMU might be 
operating either at Decreasing Returns to Scale (DRS) if a proportional increase of all inputs produces a less-thanproportional increase in outputs or Increasing Return to Scale (IRS) at the converse case. As a result, resources are supposed to transfer from DMUs operating at DRS to those operating at IRS to increase average productivity at both sets of DMUs.

The model ranking the efficient DMUs, which have an identical efficiency score equal to 1 or $100 \%$ in the standard DEA models, is called "Super Efficiency" proposed by Andersen and Petersen in 1993. The efficient DMUs herein receive efficiency scores higher than 1 or $100 \%$ by dropping the constraint that bounds the score of the evaluated DMUs. Cooper et al. (2007, p.309 to p.321) carefully explained the concept and mathematical formulation of super-efficiency in his DEA book.

In Figure 1, the two inputs $\mathrm{x}_{1}$ and $\mathrm{x}_{2}$ were used to produce the output $\mathrm{y}$. Minimum input combinations locate on the efficiency frontier connecting DMUs A, B, and C, whereas DMU D is inefficient as it produces the same output with the higher use of input.

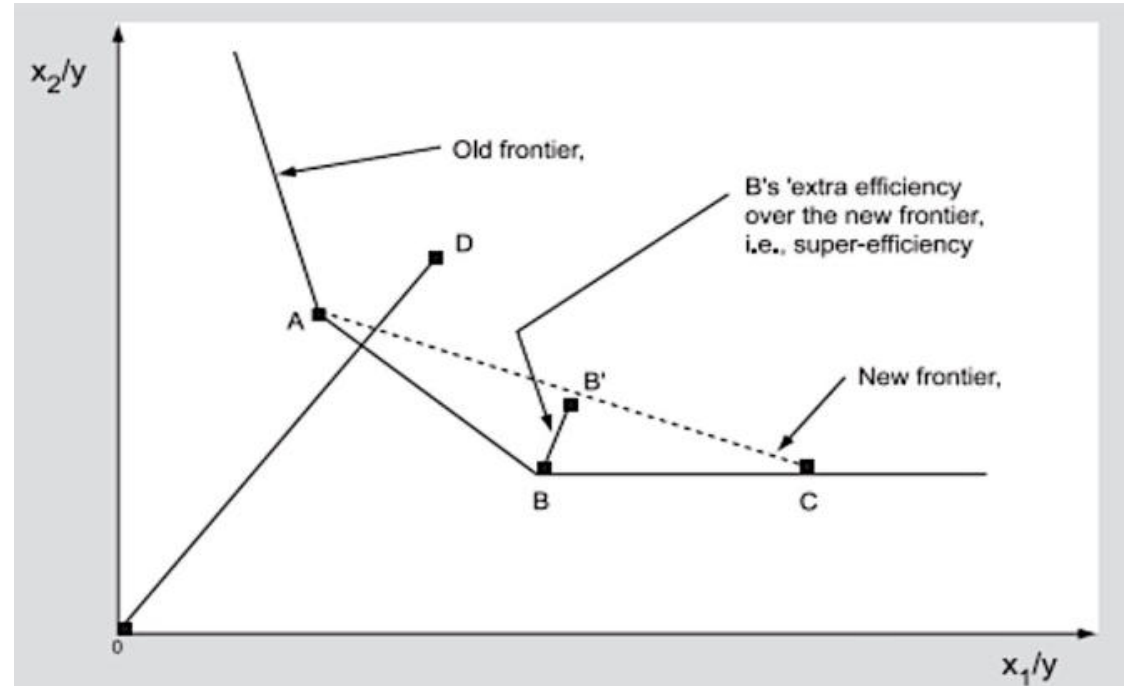

Figure 1. Standard and Super Efficiency DEA

Source: Yawe, 2010, p.84.

Further ranking of efficient DMUs is possible by computing efficiency scores over unity. Graphically, DMU B was supposed to be excluded from the old efficient frontier. Thus, a new frontier would be plotted, including only DMUs A and C. Its distance to the new frontier then calculates the super efficiency score of DMU B. The 'extra' efficiency symbolizes a permissible addition in its inputs before it was inefficient. As a result, this modification allows for efficient scores to exceed the standard efficient scores. For example, a score of $130 \%$ of DMU B means that an increase of inputs by $30 \%$ is acceptable to remain efficient (Yawe, 2010).

\section{Selection of DEA Variables and Data}

To create models on more scientific and reasonable input and output indicators, the process of selecting indicators applied to the following considerations. First, the selected variable must be consistent with the evaluation contents and study objectives. Second, it is neccessary to avoid the strong linear relationship between internal input and output variables. Third, the availability of data sources is necessary. Last, the selection of variables should base on literature reviews, and the opinions of experts, researchers in the field of microfinance.

There are two major approaches when selecting inputs and outputs regarding the operation of MFIs: intermediation approach and production approach (Athanassopoulos \& Ballantine, 1995; Fethi \& Pasiouras, 2010). Under the intermediation approach, an MFI is a financial intermediary between savers and borrowers that collect deposits and offer loans to the indigent clients to make a profit. MFIs under this approach are more or less similar to traditional banks. On the other hand, the production approach observes an MFI as a production unit that uses standard inputs to process financial services as outputs. This approach dominated the measure of MFI technical efficiency (Bassem, 2008, 2014; Ahmad, 2011), i.e., the more substantial the productivity regarding pure and scale operation, the higher the efficiency. This approach defines the goal of reaching the poor. It is more often selected 
for most MFIs as it focuses on granting loans, rather than mobilizing deposits.

Both production and intermediation approaches are concerned in this paper to provide a complete result. The inputs are standard in the literature, including total assets, number of loan officers, and operating costs. Four selected output variables include gross loan portfolio, interest and fee income, the indicator of benefit to most impoverished, and the number of women borrowers. The exhaustive list of all variables is from the Microfinance Consensus Guidelines prescribed by CGAP ${ }^{1}$ (Gutierrez-Nieto et al., 2007). Table 1 gives mnemonics, definitions, and measurement units of all selected indicators.

Microfinance was initially born to target women and the poor (social outputs), then the number of women borrowers and indicators to benefit the poorest were selected as measures of outreach. In Vietnam, microfinance has empowered women as one of the primary missions by strengthening their contribution to families, economy's roles in supporting them be more active in the development process.

Moreover, fighting against poverty is the first and foremost aim of microfinance. The problem is how to calculate the poverty index based on microfinance efficiency; or to what extent microfinance services reach and serve the poor. Because poverty is a relative concept, also referring to the general wealth of the population, the number of borrowers does not clearly explain. For example, MFIs with a high number of borrowers may lend only to better-off individuals or groups. Therefore, Microfinance Information Exchange or MIX suggested the average loan balance per borrower (in US dollar) as an indicator to measure the commitment that MFIs had been working for poverty alleviation. It is calculated as total outstanding loans divided by the number of active borrowers. It is considered as the standard proxy for clientele's poverty level and referred to the depth of outreach (Cull et al., 2009; Galema et al., 2012). Routinely, donor organizations like CGAP use this standard to measure social performance (Access, 2009). The smaller value of this number indicates the deeper reach of the MFI.

Table 1. Selected Input and Output Variables

\begin{tabular}{|c|c|c|c|}
\hline Mnemonics & Variable Name & Definition & Unit \\
\hline \multicolumn{4}{|l|}{ Input } \\
\hline $\mathbf{A}$ & Total Assets & $\begin{array}{l}\text { Total of all net asset accounts for the net of all contra-asset accounts, such } \\
\text { as the loan-loss allowance and accumulated depreciation, measures MFI } \\
\text { size. Larger size institutions might benefit from scale economies and are } \\
\text { more likely to be cost efficient in operations. }\end{array}$ & USD \\
\hline $\mathrm{C}$ & Operating Cost & $\begin{array}{l}\text { All expense from an operation includes personnel expense and } \\
\text { administrative expense but excludes financial expense and loan-loss } \\
\text { provision expense. }\end{array}$ & USD \\
\hline $\mathbf{O}$ & $\begin{array}{l}\text { Number of } \\
\text { Loan Officers }\end{array}$ & $\begin{array}{l}\text { The number of personnel whose primary activity is to manage a portion of } \\
\text { the gross loan portfolio directly. Loan officers are staff members who are } \\
\text { directly responsible for arranging and monitoring client loans. }\end{array}$ & Number \\
\hline \multicolumn{4}{|l|}{ Output } \\
\hline $\mathbf{L}$ & $\begin{array}{l}\text { Gross Loan } \\
\text { Portfolio }\end{array}$ & $\begin{array}{l}\text { They are current, delinquent and restructured loans without written-off loans } \\
\text { and interest receivable. }\end{array}$ & USD \\
\hline $\mathbf{P}$ & $\begin{array}{l}\text { Indicator of } \\
\text { Benefit to the } \\
\text { Poorest }\end{array}$ & See text for formula and its rationale. & Number \\
\hline $\mathbf{W}$ & $\begin{array}{l}\text { Number of } \\
\text { Women } \\
\text { Borrowers }\end{array}$ & $\begin{array}{l}\text { It is a modification from pieces of literature as most of the literature uses the } \\
\text { number of active borrowers. Number of active borrowers who are female, } \\
\text { measures the breadth of outreach. }\end{array}$ & Number \\
\hline $\mathbf{I}$ & $\begin{array}{l}\text { Interest and Fee } \\
\text { Income }\end{array}$ & All income on loans made to clients. & USD \\
\hline
\end{tabular}

Source: Author's synthesis.

However, Nieto et al. (2009) pointed out that the average loan balance per borrower by MIX is not satisfactory

${ }^{1}$ The largest consortium of donor agencies 
to measure the outreach in poverty reduction because of monetary units. Specifically, "the same amount of money may mean different things in different countries" (Gutiérrez-Nieto et al., 2009) based on the average per capita income. Keeping on this way, they suggested the Indicator to Benefit of poorest $\left(\mathrm{P}_{\mathrm{i}}\right)$ or Poverty index, as below:

$$
\begin{gathered}
K=\frac{A L B}{p c G N I} \\
P_{i}=1-\frac{K_{i}-\operatorname{Min}(K)}{\operatorname{Max}(K)-\operatorname{Min}(K)}
\end{gathered}
$$

$P_{i}$ ranges between 0 and 1 . The value near 1 means that the MFI has reached the poorest in society.

Where:

$\mathrm{K}$ : the ratio of the average loan balance per borrower of MFIs; $p c G N I$ : per capita Gross National Income ${ }^{2}$;

ALB: Average loan balance per borrower

In addition to overall efficiency, evaluating social and financial efficiency used different input-output specifications, as shown in Table 2. The specification concept in DEA is useful to capture how different inputs simultaneously affect multiple outputs in transformation. The estimation of various specifications has helped to analyze the efficiency score to identify the strengths and weaknesses of an MFI. The first part of the specification (i.e., ACO) includes input variables, while the second part (i.e., WP) refers to the output variables.

\begin{tabular}{|c|c|c|c|}
\hline Mnemonics & Efficiency specifications & Input variables & Output variables \\
\hline ACO-WPLI & Overall efficiency & $\begin{array}{l}\text { - Total Assets (A) } \\
\text { - Operating Cost (C) } \\
\text { - Number of Loan Officers (O) }\end{array}$ & $\begin{array}{l}\text { - Number of women borrowers (W) } \\
\text { - Indicator of Benefit to the poorest (P) } \\
\text { - Gross Loan Portfolio (L) } \\
\text { - Interest and Fee Income (I) }\end{array}$ \\
\hline ACO-WP & Overall social efficiency & $\begin{array}{l}\text { - Total Assets (A) } \\
\text { - Operating Cost (C) } \\
\text { - Number of Loan Officers (O }\end{array}$ & $\begin{array}{l}\text { - Number of women borrowers (W) } \\
\text { - Indicator of Benefit to the poorest (P) }\end{array}$ \\
\hline ACO-W & Social efficiency & $\begin{array}{l}\text { - Total Assets (A) } \\
\text { - Operating Cost (C) } \\
\text { - Number of Loan Officers (O) }\end{array}$ & - Number of women borrowers (W) \\
\hline ACO-P & Social efficiency & $\begin{array}{l}\text { - Total Assets (A) } \\
\text { - Operating Cost (C) } \\
\text { - Number of Loan Officers (O) }\end{array}$ & - Indicator of Benefit to the poorest $(\mathrm{P})$ \\
\hline ACO-LI & Overall financial efficiency & $\begin{array}{l}\text { - Total Assets (A) } \\
\text { - Operating Cost (C) } \\
\text { - Number of Loan Officers (O) }\end{array}$ & $\begin{array}{l}\text { - Gross Loan Portfolio (L) } \\
\text { - Interest and Fee Income (I) }\end{array}$ \\
\hline ACO-L & Financial efficiency & $\begin{array}{l}\text { - Total Assets (A) } \\
\text { - Operating Cost (C) } \\
\text { - Number of Loan Officers (O) }\end{array}$ & - Gross Loan Portfolio (L) \\
\hline ACO-I & Financial efficiency & $\begin{array}{l}\text { - Total Assets (A) } \\
\text { - Operating Cost (C) } \\
\text { - Number of Loan Officers (O) }\end{array}$ & - Interest and Fee Income (I) \\
\hline
\end{tabular}

\section{Table 2. DEA Specifications}

Source: Author.

${ }^{2}$ pcGNI of Vietnam in 2014 is US\$1,900. Retrieved 5 June, 2018; from: http://data.worldbank.org/country/vietnam 
In the field of microfinance, MFIs are not required to report all their activity data to the global and national databases. It is a disadvantage for current microfinance research studies due to the lace of data. Therefore, the selection of variables in this paper did purposively on data availability taken from the database of the Vietnam Microfinance Working Group or VMWG, the MIX (global web-based microfinance information platform), and the author's fieldworks. Although the data used in this paper did not cover all of MFIs in Vietnam, it is worth noting that these are the latest and most complete data used when analyzing the social and financial efficiency of the microfinance sector in the country. The sample size covered 27 major MFIs in Vietnam, mainly NGO-sponsored microfinance programs and social funds, for the year 2014.

The following Table 3 gives the values of the mean, median, the minimum and maximum range of the inputs and outputs considered under the DEA method. The mean shows the average for each variable, whereas the minimum and maximum values show the range to which the value for the specific variable extends.

Table 3. Descriptive Statistics for Variables in the Year 2014

\begin{tabular}{lcrrrr}
\hline Variable & Unit & \multicolumn{1}{c}{ MEAN } & MEDIAN & MIN & MAX \\
\hline Total Assets & USD & $278,026,442$ & $1,100,000$ & 27,978 & $6,379,050,000$ \\
Operating Cost & USD & $12,160,437.45$ & 175,097 & $37,723.97$ & $249,421,301.8$ \\
Number of Loan Officers & Number & 105 & 12 & 2 & 1316 \\
$\begin{array}{l}\text { Gross loan portfolio } \\
\text { Indicator of Benefit to the }\end{array}$ & USD & $253,243,026$ & $1,049,017$ & 27,554 & $6,001,490,599$ \\
$\begin{array}{l}\text { Poorest } \\
\text { Number of Women }\end{array}$ & Number & 0.75 & 0.81 & 0 & 1 \\
$\begin{array}{l}\text { Borrowers } \\
\text { Interest and Fee income }\end{array}$ & USD & $22,128,518$ & 247,568 & $4,905.6$ & $474,117,757.3$ \\
\hline
\end{tabular}

Source: Author's calculation.

\section{Empirical Findings}

\subsection{Overall Efficiency Scores Suggesting High Performance of Selected MFIs}

TE, PTE, and SE scores for selected MFIs were calculated and reported in Table 4.

The results reveal some critical features. 17 out of 27 MFIs are on the technical efficiency frontier under the CCR model $(\mathrm{TE}=1.00)$. Whereas, 22 MFIs are turning out to be the most efficient institutions under BBC model $(\mathrm{PTE}=1.00)$. Most of them are NGOs providing microfinance services, except for VBSP. The MFIs remaining efficient under both models such as FWD, ACE, M7MFI are good at using the inputs to generate lots of loans to targeted clients.

Moreover, the DEA results found out high average high-efficiency scores (MEAN) at 96\%, 97\%, and 99\% for TE, PTE, and SE respectively under IOM. It implies that inputs can be decreased by $3 \%$ without decreasing outputs. On the other hand, the MEAN values of TE, PTE, and SE are 96\%, 97\%, and 98\% respectively under OOM, suggesting that outputs can be increased by $3 \%$ with the current level of inputs.

The degree of MFIs achieves SE at 1 is lower than that of achieving PTE at 1 , revealing that the scale inefficiency is higher than pure technical inefficiency under both IOM and OOM. Then, the inefficiency of selected Vietnam MFIs most of the time due to the scale inefficiency rather than the technical inefficiency. The overall inefficiency is then due to producing on an inefficient scale rather than producing below the production frontier.

The results from Table 4 also show that the percentage of MFIs experienced IRS and DRS is about $3.7 \%$ and $26 \%$ under both IOM and OOM models. Therefore, an increase in inputs such as assets and the number of loan officers is essential in MFIs showing IRS like WDF and C.B to generate more outputs (number of women clients, income). On the other hand, the higher number of MFIs showing DRS like TYM and BTWU need to be noted as they are fundamentally quite large institutions in total assets and the number of credit staff in compared to remaining MFIs. 
Table 4. DEA Efficiency Score and Composition of Production Frontier

\begin{tabular}{|c|c|c|c|c|c|c|c|c|c|c|}
\hline \multirow{2}{*}{ No. } & \multirow{2}{*}{ MFI } & \multirow{2}{*}{ Legal Status } & \multicolumn{4}{|c|}{ IOM } & \multicolumn{4}{|c|}{ OOM } \\
\hline & & & $\mathrm{TE}$ & PTE & $\mathrm{SE}$ & RTS & $\mathrm{TE}$ & PTE & SE & RTS \\
\hline 1 & FWD & NGO & 1.00 & 1.00 & 1.00 & CRS & 1.00 & 1.00 & 1.00 & CRS \\
\hline 2 & DBP & NGO & 1.00 & 1.00 & 1.00 & CRS & 1.00 & 1.00 & 1.00 & CRS \\
\hline 3 & M7STU & NGO & 0.98 & 0.98 & 0.998 & DRS & 0.98 & 0.98 & 0.997 & DRS \\
\hline 4 & WV & NGO & 0.89 & 0.90 & 0.989 & DRS & 0.89 & 0.90 & 0.986 & DRS \\
\hline 5 & $\mathrm{MOM}$ & $\mathrm{SF}$ & 1.00 & 1.00 & 1.00 & CRS & 1.00 & 1.00 & 1.00 & CRS \\
\hline 6 & CAFPE & NGO & 1.00 & 1.00 & 1.00 & CRS & 1.00 & 1.00 & 1.00 & CRS \\
\hline 7 & T.HOA & NBFI & 0.98 & 1.00 & 0.976 & DRS & 0.98 & 1.00 & 0.976 & DRS \\
\hline 8 & BTV & NGO & 1.00 & 1.00 & 1.00 & CRS & 1.00 & 1.00 & 1.00 & CRS \\
\hline 9 & A.P & Other & 1.00 & 1.00 & 1.00 & CRS & 1.00 & 1.00 & 1.00 & CRS \\
\hline 10 & CWED & NGO & 1.00 & 1.00 & 1.00 & CRS & 1.00 & 1.00 & 1.00 & CRS \\
\hline 11 & M7MFI & NBFI & 1.00 & 1.00 & 1.00 & CRS & 1.00 & 1.00 & 1.00 & CRS \\
\hline 12 & $\mathrm{ACE}$ & NGO & 1.00 & 1.00 & 1.00 & CRS & 1.00 & 1.00 & 1.00 & CRS \\
\hline 13 & PPC & NGO & 1.00 & 1.00 & 1.00 & CRS & 1.00 & 1.00 & 1.00 & CRS \\
\hline 14 & $3 \mathrm{PAD}$ & $\mathrm{SF}$ & 0.54 & 0.54 & 0.991 & CRS & 0.54 & 0.62 & 0.869 & CRS \\
\hline 15 & WDF & NGO & 0.99 & 0.99 & 1.00 & CRS & 0.99 & 0.99 & 1.00 & IRS \\
\hline 16 & TYM & Other & 0.92 & 1.00 & 0.918 & DRS & 0.92 & 1.00 & 0.918 & DRS \\
\hline 17 & SEDA & NGO & 1.00 & 1.00 & 1.00 & CRS & 1.00 & 1.00 & 1.00 & CRS \\
\hline 18 & BTWU & $\mathrm{NGO}$ & 0.86 & 1.00 & 0.858 & DRS & 0.86 & 1.00 & 0.858 & DRS \\
\hline 19 & M7NP & NGO & 1.00 & 1.00 & 1.00 & CRS & 1.00 & 1.00 & 1.00 & CRS \\
\hline 20 & VBSP & Bank & 1.00 & 1.00 & 1.00 & CRS & 1.00 & 1.00 & 1.00 & CRS \\
\hline 21 & C.B & $\mathrm{SF}$ & 0.85 & 0.86 & 0.983 & IRS & 0.85 & 0.86 & 0.987 & CRS \\
\hline 22 & Dariu & NGO & 0.97 & 1.00 & 0.965 & DRS & 0.97 & 1.00 & 0.965 & DRS \\
\hline 23 & M7CDI & $\mathrm{NGO}$ & 1.00 & 1.00 & 1.00 & CRS & 1.00 & 1.00 & 1.00 & CRS \\
\hline 24 & CWCD & $\mathrm{NGO}$ & 1.00 & 1.00 & 1.00 & CRS & 1.00 & 1.00 & 1.00 & CRS \\
\hline 25 & CEP & NGO & 0.99 & 1.00 & 0.996 & DRS & 0.99 & 1.00 & 0.996 & DRS \\
\hline 26 & Co.B & $\mathrm{CU}$ & 1.00 & 1.00 & 1.00 & CRS & 1.00 & 1.00 & 1.00 & CRS \\
\hline 27 & M\&D & Other & 1.00 & 1.00 & 1.00 & CRS & 1.00 & 1.00 & 1.00 & CRS \\
\hline \multicolumn{2}{|c|}{ MEAN } & & 0.96 & 0.97 & 0.99 & & 0.96 & 0.97 & 0.98 & \\
\hline \multicolumn{2}{|c|}{ Summary } & & $\begin{array}{l}=1: \\
17\end{array}$ & $\begin{array}{l}=1: \\
22\end{array}$ & $\begin{array}{l}=1: \\
18\end{array}$ & $\begin{array}{l}\text { CRS: } \\
19\end{array}$ & $\begin{array}{ll}= & 1: \\
17 & \end{array}$ & $\begin{array}{l}=1: \\
22\end{array}$ & $=1: 18$ & CRS: \\
\hline
\end{tabular}

Source: Author's calculation.

Notes: CU: Credit Union/Cooperatives; NBFI: Non-Bank Financial Institutions; SF: Social Fund.

Table 5 presents the frequency distribution of DEA results. Generally, the variation in an efficiency level is not much. 85.19\% sampled Vietnam MFIs achieved overall technical efficiency scores over 90\%. The figures of PTE are $88.89 \%$ under both models. Similarly, the percentages of MFIs having SE above $90 \%$ were $96.30 \%$ and $92.59 \%$ under IOM and OOM respectively. A few institutions are showing the scores under $70 \%$. 
Table 5. Frequency Distribution of Efficiency Results

\begin{tabular}{|c|c|c|c|c|c|c|c|c|c|c|c|c|}
\hline \multirow{2}{*}{ Efficiency } & \multicolumn{6}{|c|}{ IOM } & \multicolumn{6}{|c|}{ OOM } \\
\hline & TE & $\%$ & PTE & $\%$ & $\overline{\mathrm{SE}}$ & $\%$ & TE & $\%$ & PTE & $\%$ & $\mathrm{SE}$ & $\%$ \\
\hline$<0.5$ & 0 & 0 & 0 & 0 & 0 & 0 & 0 & 0 & 0 & 0 & 0 & 0 \\
\hline $0.51-0.6$ & 1 & 3.70 & 1 & 3.70 & 0 & 0 & 1 & 3.70 & 0 & 0 & 0 & 0 \\
\hline $0.61-0.7$ & 0 & 0 & 0 & 0 & 0 & 0 & 0 & 0 & 1 & 3.70 & 0 & 0 \\
\hline $0.71-0.8$ & 0 & 0 & 0 & 0 & 0 & 0 & 0 & 0 & 0 & 0 & 0 & 0 \\
\hline $0.81-0.9$ & 3 & 11.11 & 2 & 7.41 & 1 & 3.70 & 3 & 11.11 & 2 & 7.41 & 2 & 7.41 \\
\hline $0.91-1$ & 23 & 85.19 & 24 & 88.89 & 26 & 96.30 & 23 & 85.19 & 24 & 88.89 & 25 & 92.59 \\
\hline Total & 27 & 100 & 27 & 100 & 27 & 100 & 27 & 100 & 27 & 100 & 27 & 100 \\
\hline Min & 0.54 & & 0.54 & & 0.86 & & 0.54 & & 0.62 & & 0.86 & \\
\hline Max & 1.00 & & 1.00 & & 1.00 & & 1.00 & & 1.00 & & 1.00 & \\
\hline Mean & 0.96 & & 0.97 & & 0.99 & & 0.96 & & 0.98 & & 0.98 & \\
\hline SD (\%) & 9.50 & & 9.24 & & 3.12 & & 9.50 & & 7.82 & & 3.86 & \\
\hline
\end{tabular}

Source: Author's calculation.

\subsection{Specifications Showing Significant Difference between Social and Financial Performance of Selected MFIS}

Analysis of the efficiency results reproduced in Table 6 and Figure 2 reveals significant points when comparing among specific efficiency scores. The average efficiency for overall financial performance (ACO-LI) is high at $92.8 \%$; however, the average score is lower under the specification ACO-L at $89.1 \%$, and the specification ACO-I at $83.7 \%$. However, the average overall social efficiency score (ACO-WP) is much lower than that of financial efficiency at 54.9\%. The average scores for ACO-P and ACO-W are only $19.6 \%$ and $50.3 \%$ respectively. It implies that MFIs in Vietnam are better at promoting women empowerment than at fighting poverty.

The results of efficiency scores showed that there is a big difference between the social and financial performance of selected MFIs. 11 MFIs that were financially 100\% efficient (ACO-LI), but only seven MFIs reached this score for social efficiency (ACO-WP). Many MFIs achieved a high score for financial performance but got a low social efficiency score. Among 27 sampled MFIs, no MFI having a social efficiency score found to be higher than the financial efficiency score, except for CWED. A typical example is Co.B, which is entirely financial efficiency $(\mathrm{ACO}-\mathrm{LI}=100 \%$ ), but its social efficiency falls to only $0.4 \%$ when calculating ACO-WP. This similar situation has appeared in many MFIs such as DBP, ACE, and PPC.

Only two MFIs, VBSP, and M\&D, are 100\% efficient under all six specifications. The efficiency scores of remaining MFIs are flexible. Choosing an example, M7NP is fully efficient under ACO-WP and ACO-LI, implying that the MFI is both social and financial efficiency. However, while the efficiency score is $100 \%$ under ACO-W, that for ACE-P is only $12.9 \%$. So, M7NP's social efficiency mainly relies on serving women by placing loans, and the institution itself does not work well on alleviating poverty. For the financial aspect, M7NP is $100 \%$ efficient under ACO-L but only $88.4 \%$ under ACO-I, implying that it is good at lending or placing loans but not so good at generating income. 
Table 6. Social and Financial Efficiency Score

\begin{tabular}{|c|c|c|c|c|c|c|c|}
\hline \multirow{2}{*}{ No. } & \multirow{2}{*}{ MFIs } & \multicolumn{3}{|c|}{ Social Efficiency } & \multicolumn{3}{|c|}{ Financial Efficiency } \\
\hline & & ACO-WP & ACO-P & ACO-W & ACO-LI & ACO-L & ACO-I \\
\hline 1 & FWD & 0.591 & 0.391 & 0.431 & 1.000 & 0.974 & 0.956 \\
\hline 2 & DBP & 0.358 & 0.182 & 0.286 & 1.000 & 0.909 & 1.000 \\
\hline 3 & M7STU & 0.408 & 0.159 & 0.394 & 0.974 & 0.964 & 0.902 \\
\hline 4 & WV & 0.306 & 0.040 & 0.306 & 0.891 & 0.889 & 0.755 \\
\hline 5 & MOM & 1.000 & 0.061 & 1.000 & 0.993 & 0.985 & 0.934 \\
\hline 6 & CAFPE & 0.759 & 0.240 & 0.701 & 1.000 & 1.000 & 1.000 \\
\hline 7 & T.HOA & 0.381 & 0.036 & 0.381 & 0.975 & 0.955 & 0.864 \\
\hline 8 & BTV & 0.574 & 0.242 & 0.546 & 0.916 & 0.833 & 0.914 \\
\hline 9 & A.P & 1.000 & 0.938 & 0.418 & 0.968 & 0.894 & 0.912 \\
\hline 10 & CWED & 1.000 & 0.212 & 1.000 & 0.477 & 0.452 & 0.429 \\
\hline 11 & M7MFI & 0.234 & 0.027 & 0.234 & 1.000 & 0.862 & 1.000 \\
\hline 12 & $\mathrm{ACE}$ & 0.400 & 0.135 & 0.400 & 1.000 & 0.952 & 1.000 \\
\hline 13 & $\mathrm{PPC}$ & 0.248 & 0.109 & 0.220 & 1.000 & 1.000 & 0.888 \\
\hline 14 & $3 \mathrm{PAD}$ & 0.309 & 0.271 & 0.147 & 0.533 & 0.533 & 0.269 \\
\hline 15 & WDF & 0.439 & 0.224 & 0.360 & 0.996 & 0.996 & 0.632 \\
\hline 16 & TYM & 0.410 & 0.007 & 0.410 & 0.897 & 0.812 & 0.897 \\
\hline 17 & SEDA & 0.396 & 0.074 & 0.395 & 1.000 & 0.996 & 1.000 \\
\hline 18 & BTWU & 0.479 & 0.098 & 0.479 & 0.821 & 0.803 & 0.745 \\
\hline 19 & M7NP & 1.000 & 0.129 & 1.000 & 1.000 & 1.000 & 0.884 \\
\hline 20 & $V B S P$ & 1.000 & 0.000 & 1.000 & 1.000 & 1.000 & 1.000 \\
\hline 21 & C.B & 0.071 & 0.000 & 0.071 & 0.847 & 0.847 & 0.208 \\
\hline 22 & Dariu & 0.457 & 0.051 & 0.457 & 0.933 & 0.860 & 0.920 \\
\hline 23 & M7CDI & 1.000 & 0.335 & 1.000 & 0.868 & 0.868 & 0.571 \\
\hline 24 & CWCD & 0.500 & 0.337 & 0.452 & 0.981 & 0.911 & 0.937 \\
\hline 25 & CEP & 0.497 & 0.005 & 0.497 & 0.996 & 0.995 & 0.974 \\
\hline 26 & Co.B & 0.004 & 0.003 & 0.002 & 1.000 & 0.754 & 1.000 \\
\hline \multirow[t]{3}{*}{27} & $M \& D$ & 1.000 & 1.000 & 1.000 & 1.000 & 1.000 & 1.000 \\
\hline & Summary & $=1: 7$ & $=1: 1$ & $=1: 6$ & $=11$ & $=5$ & $=8$ \\
\hline & MEAN & 0.549 & 0.196 & 0.503 & 0.928 & 0.891 & 0.837 \\
\hline
\end{tabular}

Source: Author's calculation 


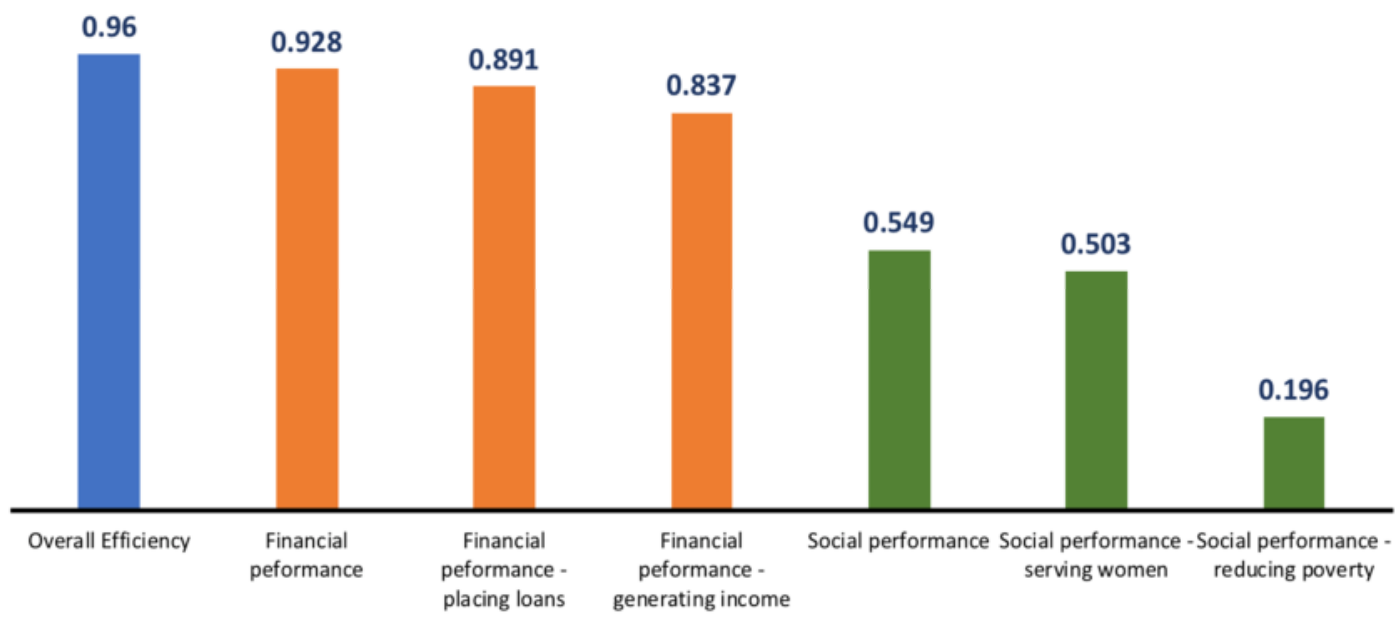

Figure 2. MEAN of Efficiency Scores

Source: Author.

Table 7 shows Pearson correlation coefficients with a significant level between social specifications and financial specifications. It is significantly different from zero at the $1 \%$ level. The correlation between social efficiency (ACO-WP) and financial efficiency (ACO-LR) is -0.057 , suggesting that they not be correlated with no statistical significance. Moreover, the Pearson correlation coefficient between efficiencies under ACO-WP and ACO-W is 0.928 , under ACO-WP and ACO-P is 0.504 , suggesting that socially efficient MFIs are more efficient in supporting women rather than poverty alleviation. On the other hand, the correlations between simplified versions of the financial specification (ACO-L and ACO-I) are positive and high at 0.629. It implies that financially efficient MFIs are efficient in both lending and obtaining income.

Table 7. Pearson Correlations between Social and Financial Efficiency Scores

\begin{tabular}{lllllll}
\hline & ACO-WP & ACO-P & ACO-W & ACO-LI & ACO-L & ACO-I \\
\hline ACO-WP & 1 & & & & \\
\hline ACO-P & 0.504 & 1 & & & & \\
& $(0.007)^{* * *}$ & & & & & \\
\hline ACO-W & 0.928 & 0.267 & 1 & & & \\
& $(0.000)^{* * *}$ & $(0.178)$ & & & & \\
\hline ACO-LI & -0.057 & 0.011 & -0.048 & 1 & 1 \\
& $(0.777)$ & $(0.958)$ & $(0.811)$ & & \\
\hline ACO-L & 0.108 & 0.0504 & 0.131 & 0.912 & \\
& $(0.591)$ & $(0.803)$ & $(0.514)$ & $(0.000)^{* * *}$ & & \\
\hline ACO-I & 0.106 & 0.0602 & 0.115 & 0.783 & 0.629 \\
& $(0.578)$ & $(0.766)$ & $(0.567)$ & $(0.000)^{* * *}$ & $(0.000)^{* * *}$ & \\
\hline
\end{tabular}

Source: Author's calculation

Note: $* * *, * *$, and $*$ indicate coefficients are significant at $1 \%, 5 \%$ and $10 \%$ level respectively

\subsection{Ranking MFIs}

The super efficiency score has been estimated to rank efficient MFIs. Figure 3 shows the relationship between financial and social efficiency by ranking the MFIs based on their super social and financial efficiency score. 


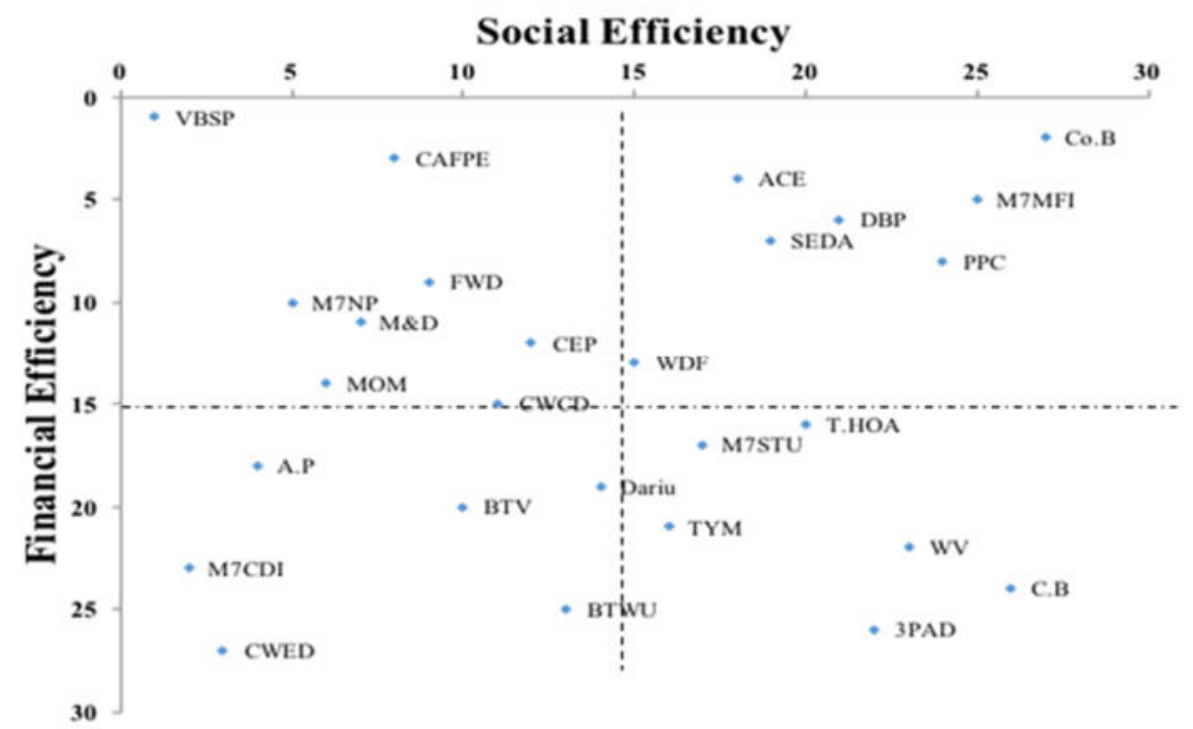

Figure 3. Comparative Ranking of Social and Financial Efficiency Based on Super Efficiency Scores

Source: Author's calculation

The result helps to divide sampled MFIs into four quadrants to express different groups of performance.

(1) The group on the upper left-hand corner gathers MFIs with relatively high financial and social efficiency. VBSP, located in the extreme corner of the graph, is $100 \%$ efficiency from both points of view. Other institutions, including CAFPE, FWD, M7NP, and M\&D, have performed well with high relative ranks in both measures of efficiency. These MFIs could be "the industry leaders."

(2) The top right-hand corner of the figure is the group of MFIs with financially efficient but socially inefficient. These MFIs could maintain their financial efficiency and improve the social side by, for example, granting smaller loans to more clients.

(3) The third quadrant on the bottom left-hand corner includes MFIs that achieve social efficiency but financial inefficiency. BTWU is the typical case in this group that claims to lend only to poor women.

(4) The fourth quadrant is on the lower right-hand side corner groups MFIs with low ranks of both social and financial efficiency. These institutions should reconsider their development strategy and action plan. Otherwise, they will run the risk of not being able to survive for long.

In short, choosing between financial efficiency and social efficiency has always been a matter for MFIs. The institutions would target financial performance as a guarantee to reach their social objectives. These results can conclude that a socially efficient MFI is also financially efficient in Vietnam.

\section{Conclusion}

MFIs in Vietnam are generally efficient with overall technical efficiency is $96 \%$ under both the input- and outputoriented models. More specifically, NMPs are more socially efficient than other types of MFIs. It can be translated that NGOs, primarily non-profit organizations, have microfinance activities that are always trying to keep their social goals.

However, the efficiency scores have shown a significant difference between the social and financial performance. Overall scores only reached $54.9 \%$, while the financial scores reached $92.8 \%$. The operational strategies of selected MFIs appear to be unsuccessful in serving poor women and reducing poverty. Instead, profitable activities, such as interest-based lending are more concentrated. Moreover, with only one exception (VBSP), there are no MFIs that are socially efficient but financially inefficient. It is consistent with the view that in order to meet the social responsibilities, MFIs have to be at first financially sound.

The evaluation of different efficiency forms also discovered the leading performers in the microfinance sector. These MFIs attained high-efficiency scores on social and financial aspects, referring to the capability on cost control, operation improvement, and management activities. By contrast, the analysis revealed a series of MFIs whose efficiency is low both from the financial and social points of view. Their current operation could cause their 
future uncertain. Then, the policymakers need to be careful when deciding on the operation and development of these MFIs.

In summary, this paper contributes to scare research in the microfinance field. Selected MFIs in Vietnam are generally less attractive in moving upward since their objectives and mission are not specific. The focus on either alleviating poverty or being profitable or both may lead to a significant difference in evaluating MFIs' efficiency scores.

\section{References}

Access, F. (2009). Measuring access to financial services around the world. Consultative Group to Assist the Poor/the World Bank.

Ahmad, U. (2011). Efficiency analysis of micro-finance institutions in Pakistan. Munich Personal REPEC Archive (MPRA) Report, No. 34215

Akram, W., Shan, S., Shaikh, S., \& Yashkun, U. U. (2016). Determinants of Microfinance Institutions' Efficiency in South Asia during Financial Crisis: A Two-Stage Analysis. Pakistan Journal of Social Sciences (PJSS), 36(2), 1089-1099.

Athanassopoulos, A. D., \& Ballantine, J. A. (1995). Ratio and frontier analysis for assessing corporate performance: evidence from the grocery industry in the UK. Journal of the Operational Research Society, 46(4), 427-440.

Azad, M. A., Munisamy, S., Masum, A. K., \& Wanke, P. (2016). Do African microfinance institutions need efficiency for financial stability and social outreach? South African Journal of Science, 112(9-10), 1-8.

Balkenhol, B., \& Hudon, M. (2011). Efficiency. In The Handbook of Microfinance, World Scientific Publishers (pp. 383-396).

Banker, R. D., Charnes, A., \& Cooper, W. W. (1984). Some models for estimating technical and scale inefficiencies in data envelopment analysis. Management science, 30(9), 1078-1092.

Bassem, B. S. (2008). Efficiency of microfinance institutions in the Mediterranean: an application of DEA. Transition Studies Review, 15(2), 343-354.

Bassem, B. S. (2014). Total factor productivity change of MENA microfinance institutions: A Malmquist productivity index approach. Economic Modelling, 39, 182-189.

Berger, A. N., \& Humphrey, D. B. (1997). Efficiency of financial institutions: International survey and directions for future research. European journal of operational research, 98(2), 175-212.

Bruett, T., Barres, I., Curran, L., Escalona, A., Nelson, E. P., Norell, D., \& Stephens, M. (2005). Measuring performance of microfinance institutions. Washington: SEEP Network.

Charnes, A., Cooper, W. W., \& Rhodes, E. (1978). Measuring the efficiency of decision-making units. European journal of operational research, 2(6), 429-444.

Coelli, T. J., Rao, D. S. P., O'Donnell, C. J., \& Battese, G. E. (2005). An introduction to efficiency and productivity analysis. Springer Science \& Business Media.

Cooper, W. W., Seiford, L. M., \& Tone, K. (2006). Introduction to data envelopment analysis and its uses: with $D E A$-solver software and references. Springer Science \& Business Media.

Cooper, W. W., Seiford, L. M., \& Zhu, J. (Eds.). (2011). Handbook on data envelopment analysis (Vol. 164). Springer Science \& Business Media.

Cooper, W. W., Seiford, L. M., Tone, K., (2007). Data envelopment analysis: a comprehensive text with models, applications, references and DEA-solver software, 2nd edition. Springer, New York.

Cull, R., Demirgüç-Kunt, A., \& Morduch, J. (2009). Microfinance meets the market. Journal of Economic perspectives, 23(1), 167-92.

Fethi, M. D., \& Pasiouras, F. (2010). Assessing bank efficiency and performance with operational research and artificial intelligence techniques: A survey. European journal of operational research, 204(2), 189-198.

Fuller, R. J., \& Crawford, R. H. (2011). Impact of past and future residential housing development patterns on energy demand and related emissions. Journal of housing and the built environment, 26(2), 165-183.

Galema, R., Lensink, R., \& Mersland, R. (2012). Do powerful CEOs determine microfinance performance? Journal of Management Studies, 49(4), 718-742. 
Gutiérrez-Nieto, B., Serrano-Cinca, C., \& Molinero, C. M. (2007). Microfinance institutions and efficiency. Omega, 35(2), 131-142.

Guitiérrez-Nieto, B., Serrano-Cinca, C., \& Molinero, C. M. (2008). A DEA approach to microfinance institutions efficiency. In centre for European research in microfinance seminars, Brussels.

Gutiérrez-Nieto, B., Serrano-Cinca, C., \& Mar Molinero, C. (2009). Social efficiency in microfinance institutions. Journal of the operational research society, 60(1), 104-119.

Kipesha, E. F. (2013). Performance of microfinance institutions in Tanzania: integrating financial and Nonfinancial metrics. European Journal of Business and Management, 5(4), 94-105.

Mokhtar, H. S. A., AlHabshi, S. M., \& Abdullah, N. (2006). A conceptual framework for and survey of banking efficiency study. UNITAR e-Journal, 2(2), 1-19.

Qayyum, A., \& Ahmad, M. (2006). Efficiency and sustainability of micro finance. Munich Personal REPEC Archive (MPRA) Paper, No. 11674.

Reynolds, D., \& Thompson, G. (2002). Multi-unit restaurant-productivity assessment: a test of data-envelopment analysis. Cornell University, Ithaca, NY.

Rosenberg, N., \& Nathan, R. (1994). Exploring the black box: Technology, economics, and history. Cambridge University Press.

Worthington, A. (2000). Cost efficiency in Australian non-bank financial institutions: A non-parametric approach. Accounting \& Finance, 40(1), 75-98.

Yawe, B. (2010). Hospital performance evaluation in Uganda: a super-efficiency data envelope analysis model. Zambia Social Science Journal, 1(1), 6. 